\title{
Lightweight ceramsite concrete used as an additional protection of fuel oil tanks on ships
}

\author{
Marcin Jeżewski \\ Cezary Krasowski \\ Barg M.B. Gdańsk, Sp. z o.o.
}

\begin{abstract}
Introduction of the semi-elastic barrier into ship fuel tanks requires of use of core material which will play role of carrier for elastic, fuel resistant layer. Such core material should be ligth, non reactive with water and fuel, fire resistant, corrosion neutral and finally easy applicable and relatively cheap. In paper the different problems like components, preparation, application as well as surface treatment for using of the light concrete as core material are presented.
\end{abstract}

Keywords: light concrete, core material, fuel tank protection

\section{INTRODUCTION}

Concrete is one of the most commonly applied materials for building structures. It has achieved its popularity due to specific properties which allow for its very wide application. The concrete applied directly in situ, the so called 'fresh concrete' is characterized by a high plasticity and workability, that makes it possible to form building structures almost without any limits. The concrete formed in the structure hardens very fast due to its hydratation processes, that gives appropriate strength and durability to building objects. A relatively simple way of concrete manufacturing, accessibility of its components, as well as wide range of its applications conditioned by many kinds of the material, have resulted in that the concrete is the most frequently used material for building structures. Such situation entails fast development of concrete technology. Many reserach projects aimed at improvement and modification of basic features of concrete are carried out worldwide. This is a material which continuously undergoes evolution, trying to cope with more and more sophisticated architectural requirements.

Concrete is a composite which is mainly formed of three components: binder, aggregate and water. Chemical admixtures and mineral additives, cut steel wires, natural and artificial fibres are also applied to it. After mixing the components together, a concrete mixture is obtained in the form of a viscous - plastic - solid body which is transformed into a solid body changing its features during further hardening (curing) process. The components of concrete of many types and classes can be found, that makes it possible to get mixtures of very different features and applications. The features can be additionally modified by introducing chemical admixtures and mineral additives. The so produced concrete is capable of transferring very large structural loads (high strength concretes), providing high durability for engineering objects (high durability concretes) or filling structural spaces (lightweight concretes), as well as it is suitable for many other applications in contemporary building industry.

The diversity of concrete mixtures, achieved by appropriate selection of particular types of main components, admixtures and additives, makes that their utility features begin drawing attention of other branches too, not only of building industry. One of the attempts to using the concrete features to other applications is the project of an additional protection layer made of concrete for ship fuel oil tanks and cargo tanks on tankers. This is a layer intended for separating ship's structure from a polyurethane coating which constitutes also a protective element of tanks. In the project the use is made of a relatively high strength of concrete associated with its rather low volumetric density (important for overall weight of ship), as well as its full fire resistance and durability implying a long service life. This paper presents an approach to implementation of concrete engineering and materials science to designing a concrete mixture which complies with criteria of the project. Below, ways of selection of particular components of the concrete, its manufacturing and material application, are presented.

\section{SELECTION OF LIGHTWEIGHT CONCRETE COMPONENTS}

One of the main features of concrete mixture deciding on selection of its components was its volumetric density. With a view of minimization of additional weight of ship one tried to obtain a concrete of as low volumetric density as possible with maintained maximum values of its strength and durability parameters.

A lightweight aggregate concrete distinguished - out of other kinds of concrete - by a relatively low volumetric 
density at maintained high strength and durability parameters, best corresponds with the criterial parameters. Low value of the volumetric density is one of the basic features of lightweight concretes whose mechanical and physical properties depend on it. According to its definition the lightweight concrete volumetric density has not to exceed the value of $2000 \mathrm{~kg} / \mathrm{m}^{3}$.

It depends on:

$\star$ kind and amount of aggregate

$\star$ structure of concrete

$\star$ amount of cement

$\star$ amount of water absorbed by the aggregate.

Depending on a degree of concrete humidity the concrete volumetric density is differentiated into : that in dry state (of $0-3 \%$ humidity), that in dry-air state (of $6-9 \%$ humidity) and that in fresh state -after consolidation in curing phase (of $14-18 \%$ humidity). In common concretes volumetric density changes are small, but in the case of lightweight ones the changes can reach $20-25 \%$.

The aggregate takes up a prevailing part of the whole volume of concrete (60-75\%). Its appropriate selection is the most important element of designing the low-density concrete mixture. The best choice in this respect is associated with lightweight aggregates, and such kind of aggregate was selected in the case of the project in question.

Below (Fig. 1), values of the concrete volumetric density are presented depending on the used aggregate.

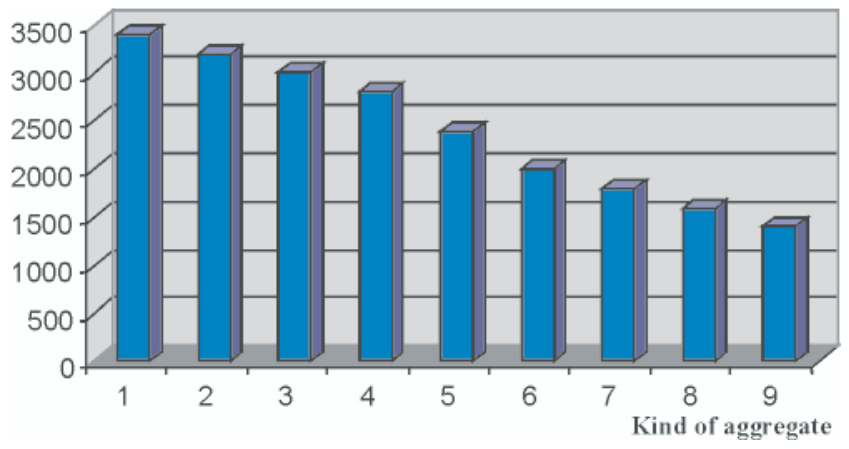

Fig. 1. Concrete volumetric density in function of used aggregate $\mathrm{kg} / \mathrm{m}^{3}$. 1-3 - Heavy aggregates - e.g. granite, basalt, 4-6 - Usual aggregates - e.g. glacial gravels, 7-9 - Lightweight aggregates - e.g. pollytag, ceramsite

Out of the large group of lightweight aggregates the ceramsite aggregate was selected. The ceramsite is obtained by burning silts and clays capable of bloating under exposure to heat. To this end the raw material is mixed with water till a dense consistence is achieved, and the so obtained mass is burnt in rotary furnaces in the temperature of abt. $1250^{\circ} \mathrm{C}$. The bloating of clays and their possible refining leads to manufacturing a ceramsite of high strength and low density.

The ceramsite aggregate makes it possible to obtain the concrete of the strength reaching about $20 \mathrm{MPa}$ and the volumetric density close to $1000 \mathrm{~kg} / \mathrm{m}^{3}$. Also, llytag ash-porite aggregate of a greater strength was considered. The strength increase was obtained at the expense of a significant increase of the volumetric density of the aggregate and for this reason it was rejected.

The next element of the designing of the mixture was to select an appropriate binding material. For lightweight aggregate concretes CEM I 32.5 Potland cements are used. Such material contains at least $95 \%$ of clinker and a minimum amount of additives. The so high content of clinker entails a very fast rise of concrete strength - even up to $90 \%$ of final strength - during the first week of curing. Maximum strength values of such cements have to be not lower than $32.5 \mathrm{MPa}$. The fast rise of concrete strength is of a great importance in practice as it makes it possible, after a short time from its application, to dismount constructional forms and to carry out further operations. This way down-time intervals due to concrete curing (hardening) can be minimized. To obvious drawbacks of application of CEM I cements belongs its large heat of hydratation, that leads to generation of thermal stresses and consequently can result in producing the cracks and weakening the structure. Such effects can be counteracted by adding fly-ash and applying a proper thermal insulation to a given element, that prevents from occurrence of large temperature gradients in it. The problem is mainly associated with large massive concrete objects.

Below (Fig. 2), the diagram of the mean strength rise of CEM I 32.5 cement slurry in function of time is presented.

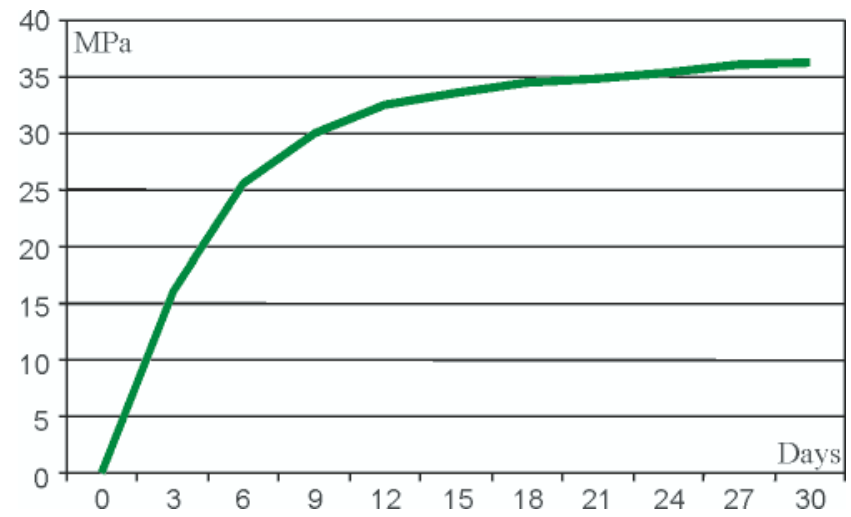

Fig. 2. Strength rise of CEM I 32.5 cement slurry versus time

For the designed lightweight aggregate concrete an addition of fly-ash was used. The fly-ash has a form of fine mineral dust of light-to-dark grey or light brown colour. It is mainly consisted of silicon, aluminium and ferric oxides. Moreover it contains, like natural rocks, various trace elements and shows a small amount of coke. As a result of thermal processing in fire chamber the fly-ash produced of hard coal enters the pozzolan reactions in presence of $\mathrm{Ca}$ in room temperature. This way, like in Portland cement hydratation process, tiny cristalic $\mathrm{Ca}-\mathrm{Si}$ and $\mathrm{Ca}-\mathrm{Al}$ hydrates which consolidate themselves into a hard rock material, are produced. The application of the additive in question was aimed at improvement of reologic parameters of concrete, that makes it possible to obtain an optimum workability of concrete mixture for applying it to ship steel elements.

The use of fly-ash makes also it possible to reduce consumption of cement - the most expensive component of concrete mixture - hence this is of a great economic importance. The fly-ash - due to its pozzolan features - takes part in mixture hardening. Also, as a result of it application, heat of hydratation is lowered and initial rise of concrete strength is mitigated. A plastifying admixture was a successive component used in designing the lightweight concrete. Admixtures are used for successive improvement of features of concrete mixture and hardening concrete. A wide range of action of the admixtures makes it possible to select an appropriate substance for almost any concrete mixture to be prepared.

The admixtures are usually added to concrete in an amount not greater than $5 \%$ of cement mass. They can be both organic and non-organic substances of chemical, physical or chemical and physical influence. They can interact already during mixing the components or just in cured concrete. They can modify a few features, a part of which can become improved and the other - worsened. 
In the case in question the super-plastificator admixture based on multi-carboxilate was applied. As a result of the application of the admixture, liquidity of the mixture - hence also its workability - was increased, and amount of applied water was lowered at maintained cement content, that led to a greater concrete strength. Such kind of admixture is intended for cements of fast rising strength.

For manufacturing the concrete mixture, tap water satisfying all relevant requirements according to $\mathrm{PN}-\mathrm{EN}$-standards was used.

\section{MANUFACTURING THE LIGHTWEIGHT CERAMSITE CONCRETE}

\section{General recommendations}

In accordance with a working recipe determined in advance, particular components of concrete are dosed in the following order : aggregate, possible fly-ash or natural sand additive, 1/2-3/4 amount of working water, cement and the remaining part of water. If aerating - plastifying additives are used their solution should be dosed last - after initial mixing the components. Before dosing the ceramsite its moisturing is recommended (using abt. 1/2 amount of working water). In the case of cement its dosing should be done by weighing, and in the case of aggregates - by weighing or volume measuring after determination value of bulk density of a given aggregate. Attention should be paid to water dosing. Changeable initial wetness of aggregate and progressing process of its moisturing can make it difficult to obtain a proper consistence of the mixture, which may require to be corrected.

The mixing should be performed mechanically - the best way is to apply forced, concurrent or backward mixing. Time of mixing should be not shorter than $3 \mathrm{~min}$. If chemical aerating and plastifying additives are used the mixing time should be longer.

The ceramsite aggregate concrete mixtures which have less dense consistence, can be susceptible to segregating the components. Hence their transport should be performed in such way as not to cause segregation and changes in their composition. A seperate problem is the mixture's transport by pumping. High absorption capacity of aggregate makes that a part of working water - under pressure - developed during concrete pumping - is pressed into aggregate volume, that results in densification of the pumped mixture and consequently - blocking the pipelines. To make ceramsite concrete easy for pumping the aggregate should be mositured in advance and the concrete of a good workability should be designed.

Application of the ceramsite concrete mixture should be made uniformly over the whole surface of the form, and the throwing of the mixture from a greater height and placing of the concrete in the form of cone should be avoided as it may lead to partial segregation of the mixture. Application of aerating admixtures prevents the concrete mixture from segregation. Complete filling the form by the mixture should be finished before $30 \mathrm{~min}$ passing from the end of the mixing of components. Densification of the mixture should be done by using immersing vibrators of high frequencies and low amplitudes of vibration.

\section{Recipe}

The below given content of $1 \mathrm{~m}^{3}$ of the concrete mixture was determined as a result of application of the general principles of concrete mixture designing with taking into account specificity of application of lightweight aggregates as well as results of verification of preliminary design assumptions by laboratory tests :

$\begin{array}{ll}\text { CEM I } 32.5 \text { cement } & -350 \mathrm{~kg} \\ \text { Ceramsite } & -450 \mathrm{~kg} \text {, fractions from } 0-20 \mathrm{~mm} \\ \text { Fly-ash } & -150 \mathrm{~kg} \\ \text { Water } & -2501 \\ \text { Super-plastificator } & -0.3 \% \text { of cement mass. }\end{array}$

The above given recipe was prepared for ceramsite concrete of a firm structure. Degree of filling the void spaces between aggregate particles by cement slurry should be not smaller than $85 \%$. The concrete of firm structure - in contrast to that having cavities or semi-firm one - is characterized by a greater compressive strength and greater workability, obtainable especially after adding fly-ashes and plastifying additives. Elaboration of a precise recipe for lightweight aggregate concrete mixture brings about certain difficulties. Because of high absorbability of lightweight aggregate as well as its suceptibility to segregation such recipe should be currently verified during production process and introduction of necessary corrections, mainly to amount of dosed water, should be possible.

\section{Manufacturing process}

In the case in question the first step in manufacturing of concrete mixture was to soak the aggregate in about $50 \%$ amount of working water. Next, in line with the above mentioned principles of sequencing the component addition, the components were mixed in a mixer up to the state of a uniform, non-separating, dense plastic mass. The remaining amount of working water was then added under continuous control of the slurry's consistence in order to prevent the mixture from excessive liquefaction, that could make correct application of the concrete impossible and its segregation easier. After obtaining its appropriate consistence and sufficient degree of mixing its components, the mixture was placed onto a ship plating element. For the mixture placing the immersing vibrators were applied in order to obtain its uniform distribution. Correctly manufactured concrete well spreads, does not leave void spaces and does not segregate or stratify its components.

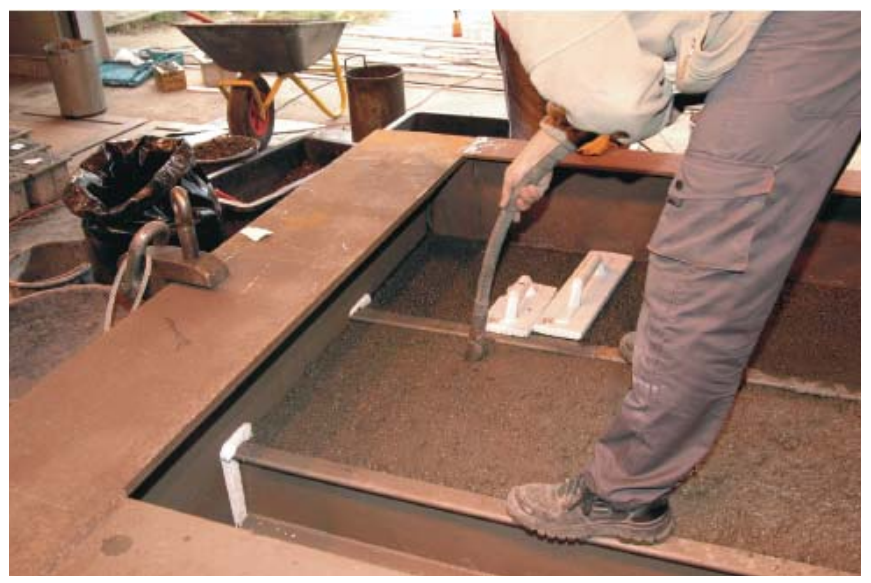

Fig. 3. Application of the concrete into the ship bottom structure

The so prepared concrete mixture showed - during laboratory tests - the values of volumetric density in the range of $1100-1200 \mathrm{~kg} / \mathrm{m}^{3}$, and the values of the compressive strength after 28 days of curing - in the range of 12-14 MPa. Application of the pozzolan fly-ash additive makes it possible to expect a further rise of the compressive strength by about $10-15 \%$ of its value after 28 -day curing. 

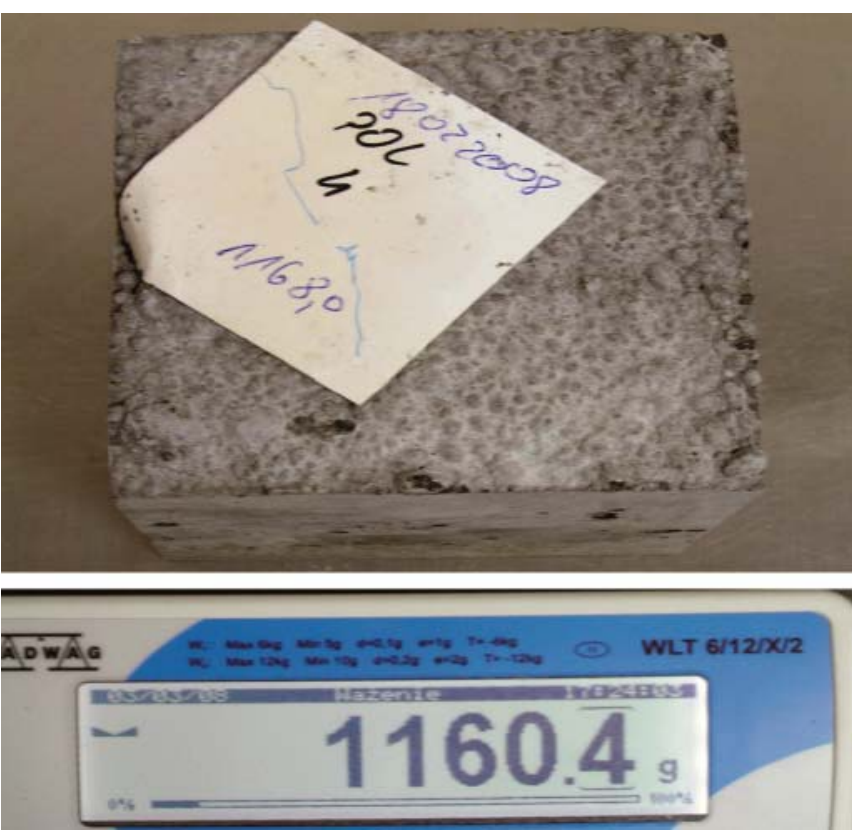

Fig. 4. Exemplary view and weight of the ligth concrete specimen

\section{ADHESION BETWEEN CONCRETE AND STEEL}

In the project in question the concrete used as a filler of void spaces in ship side structure, comes into direct contact with hull structural steel and polyurethane coating layer. Degree of concrete adhesion to those layers highly affects strength of the whole system. To improve adhesion of all the layers epoxy resins of two kinds with addition of quartz sand, which formed - together with the remaining components - the below presented structure, were applied :

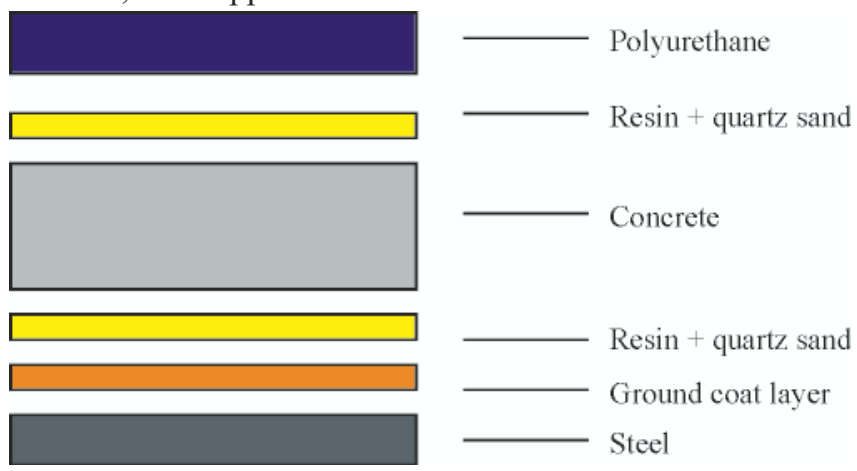

Fig. 5. Layer structure of the typical elastic barrier supported by light concrete core

Hull steel elements were covered with a ground coat layer of an epoxy resin of anti-corrosion properties. The layer is intended for protection of hull plating as well as for making it possible to apply successive layer of another kind. The next layer of epoxy resin of somewhat different properties, applied onto the ground coat, comes into direct contact with concrete. To increase contact area and adhesion power, the quartz sand poured directly on freshly laid resin, was used. On the so prepared background the concrete mixture was laid after about $48 \mathrm{~h}$ of curing. After the initial curing phase of the concrete its upper layer was also covered by the resin and quartz sand, that was aimed at improving the adhesion between the polyurethane layer and concrete.

In order to verify adhesion power between the polyurethane layer and concrete the pull-off test showing the degree of adhesion depending on materials applied to contact of layers, was performed.

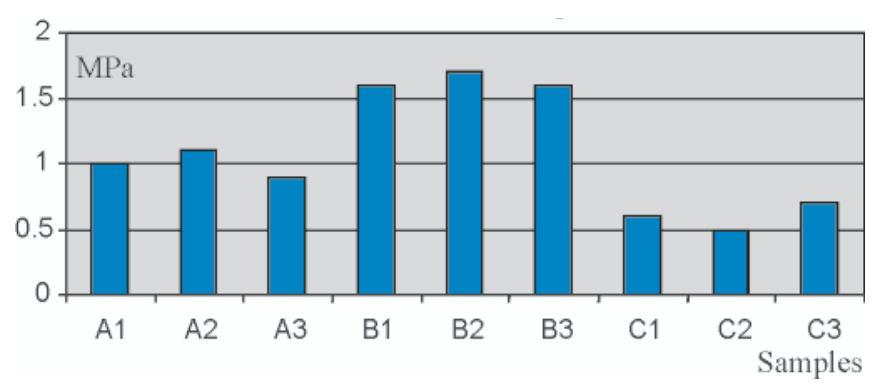

Fig. 6. Pull-off strength test result of adhesion between concrete and polyurethane layer. $\boldsymbol{A}$ - samples with epoxy resin, $\boldsymbol{B}$ - samples with epoxy resin + quartz sand, $\boldsymbol{C}$-samples without epoxy resin

The test results clearly showed that the greatest degree of adhesion between polyurethane layer and concrete was obtained by applying the epoxy resin and quartz sand simultaneously.

During the pull-off testing much greater values of degree of steel-to-concrete adhesion were achieved for the samples with applied two layers of epoxy resin combined with quartz sand.

\section{SUMMARY}

The lightweight aggregate concrete designed with application of the above presented principles is a very good filling material for protection barrier to be applied to ship fuel oil tanks and oil cargo tanks in tankers. Its volumetric density in the range of $1100-1200 \mathrm{~kg} / \mathrm{dm}^{3}$ and compressive strength ranging from 12 to $14 \mathrm{MPa}$ seem to be a good compromise between low unit mass and suficient strength. Correctly manufactured concrete mixture ensures also to obtain high durability, hence a long service life.

In designing and manufacturing the lightweight aggregate concrete one should remember about specific features of such kind of concrete, especially about high absorbability of the aggregate which should be soaked in advance to avoid possible changes in mixture's consistence during its working process, consequently - changes in its properties assumed in the design stage.

The application of epoxy resin layers greatly improves adhesion of particular layers of the protection system, that leads to rise of its strength and durability.

The selection of all the specified components of lightweight concrete was performed not only with a view of technological reasons, but also economical ones.

The selected components are widely available on the market at competitive prices.

\section{BIBLIOGRAPHY}

1. Jamroży Z.: Concrete and its engineering methods (in Polish). Scientific publishing house PWN, Warszawa 2008, Third issued

2. Nagrodzka-Godycka K.: Laboratory testing of concrete and ferroconcrete properties (in Polish). Publisher Arkady Sp. z o.o. Warszawa, 1999

3. Jóźwiak I., Kliszczewicz R.: Design principles of ferroconcrete structures (in Polish). Publisher Arkady Sp. z o.o. Warszawa, 2001

4. Czarnecki L., Broniewski T, Henning O.: Chemistry in building engineering (in Polish). Publisher Arkady Sp. z o.o. Warszawa, 1996

5. Peukert St.: Cements of common and special use (in Polish). Polish Cement Sp. z o.o., 2000

6. Collective work ed. by L.Czarnecki : Concrete complying with provisions of PN-EN 206-1 Standard. A commentary (in Polish). Polish Cement Sp. z o.o., 2004

7. Neville A. M.: Properties of concrete (in Polish). Polish Cement Sp. z o.o., 2000

8. Piasta J., Piasta W.G.: Common concrete (in Polish). Publisher Arkady Sp. z o.o. Warszawa, 1994 